\title{
IBM DAGUSIBU OBAT DAN PEMERIKSAAN KESEHATAN BAGI PEKERJA MIGRAN INDONESIA (PMI) DI TAIPEI, TAIWAN
}

\author{
Sendi Lia Yunita ${ }^{1)}$, Rizka Novia Atmadani') \\ 1)Program Studi Farmasi, Fakultas IImu Kesehatan, Universitas Muhammadiyah Malang, Malang, Jawa Timur, Indonesia \\ Corresponding author : Sendi Lia Yunita \\ E-mail : sendi@umm.ac.id
}

Diterima 17 Maret 2021, Direvisi 24 Maret 2021, Disetujui 26 Maret 2021

\begin{abstract}
ABSTRAK
Pengobatan mandiri (swamedikasi) dilakukan untuk mengobati penyakit ringan yang bersifat simptomatis. Namun demikian upaya swamedikasi pada masyarakat belum diikuti dengan pengetahuan yang tepat dalam mendapatkan, menggunakan, menyimpan dan membuang (DAGUSIBU) obat secara utuh. Hal ini tidak hanya terjadi pada masyarakat di dalam negeri tapi juga dialami oleh para pekerja migran Indonesia (PMI) yang ada di luar negeri termasuk di Taipei, Taiwan. Metode pengabdian yang telah dilaksanakan meliputi pemeriksaan kesehatan, konsultasi kesehatan gratis dan penyuluhan tentang DAGUSIBU melalui pemeriksaan tekanan darah, berat badan, kadar gula darah, kadar asam urat, kadar kolesterol menggunakan kit dan penyuluhan dengan menggunakan bantuan brosur. Kegiatan pengabdian ini bertujuan untuk memberikan pelayanan kesehatan dan informasi tentang DAGUSIBU obat serta sebagai bentuk asesmen awal dan pencegahan penyakit para pekerja migran Indonesia di Taipei. Kegiatan pengabdian berjalan dengan efektif dimana respon partisipan cukup baik dengan didapatkan 51 orang. Dimana beberapa pemeriksaan kesehatan menunjukan hasil di atas batas normal, yaitu 3 orang untuk pemeriksaan kadar gula darah, 2 orang pemeriksaan kadar kolesterol dan 5 orang untuk pemeriksaan kadar asam urat.
\end{abstract}

Kata kunci: DAGUSIBU; kesehatan; PMI; Taipei; Taiwan

\begin{abstract}
Self-medication is an effort to eliminate the symptomatics minor ailments. However, this efforts have not been followed by proper knowledge in obtaining, using, storing, and disposing (DAGUSIBU) of medicine completely in the community. Its does not only happen to people in the country but also experienced by Indonesian migrant workers (PMI) who are abroad, including in Taipei, Taiwan. The community service method that have been carried out included free examinations, free health consultations, and socialization of DAGUSIBU through examining blood preasure, body weight, blood sugar levels, uric acid levels, cholesterol levels using kits, and socialization using brochures. The objectives of this activities can provided the health services and information about DAGUSIBU of medicine as weel as an initial assessment and prevention of diseases among Indonesian migrants workers in Taipei.This effective activities which are the participants response is quite good with 51 participants was carried out. Several results test showed above the normal limitation, namely 3 participants checked sugra blood level, 2 peoples checked cholesterol levels, and 5 peoples checked uric acid levels.
\end{abstract}

Keywords: DAGUSIBU; health; Indonesian Migrant worker; Taipei; Taiwan

\section{PENDAHULUAN}

Saat ini peningkatan konsumsi dan kesadaran penggunaan obat secaa mandiri di masyarakat belum diikuti dengan peningkatan pengetahuan perlakuan terhadap obat itu sendiri (Djuria, 2018). Masyarakat mulai sadar akan pengobatan namun hal tersebut belum diikuti dengan pengetahuan yang benar. Saat ini, sebagian besar masyarakat melakukan pengobatan sendiri (swamedikasi) khususnya untuk penyakit-penyakit ringan atau yang bersifat simptomatis. Akan tetapi tidak diikuti dengan pengetahuan yang tepat (Jayanti et al.,
2020). Pada penelitian di Surabaya, terdapat hanya $42 \%$ responden yang mengetahui bahwa anatasida harus dikunyah dahalu sebelum ditelan (Putra et al., 2017). Selain itu, pemahaman tentang penggunaan dan penyimpanan supositoria yang tepat juga masih minim yaitu sekitar $56 \%$ pada penelitian di Puskemas Pringsewu (Ulfa, JK, \& Sobirin, 2018). Begitu juga pada pemahaman akan pemusnahan obat rusak atau kadaluarsa yang masih terbatas (Nugraheni, Ganurmala, \& Pamungkas, 2020), misalnya bentuk sediaan syrupus bukan langsung dibuang ke tempat 
sampah tetapi dibuang di saluran pembuangan dengan air mengalir. Pengetahuan yang benar tentang hal-hal tersebut masih minim dipahami oleh masyarakat padahal konsumsi obat cukup meningkat (Djuria, 2018). Fenomena seperti ini banyak terjadi di masyarakat pada saat ini (Djuria, 2018; Jayanti et al., 2020; Nugraheni et al., 2020; Ulfa et al., 2018). Oleh karena itu sangat dibutuhkan peningkatan pengetahuan yang akan sangat bermanfaat untuk meningkatkan taraf kesehatan masyarakat terutama dengan tingkat pendidikan dasar. Salah satunya adalah Pekerja Migran Indonesia (PMI) yang berada di luar Negeri. Dalam beberapa dekade ini, pengiriman PMI ke luar negri mengalami peningkatan yang cukup besar bahkan berbanding terbalik dengan pola perburuhan Indonesia pada masa kolonial (Ningsih, 2018).

PMI di Taiwan mencapai 263.358 jiwa dan Taipei merupakan ibukota Taiwan yang menjadi pusat kegiatan PMI (KDEI, 2021). Dimana hampir sebagian besar kegiatan dilakukan di Taipei karena sangat mudah untuk dicapai. Latar belakang PMI cukup beragam baik dari segi sosial, ekonomi, budaya maupun pendidikan. Keanekaragaman tersebut dapat menggambarkan kondisi ketenagakerjaan masyarakat Indonesia pada umumnya (KDEI, 2021).

Ipteks bagi masyarakat yang diberikan adalah berupa pemeriksaan kesehatan dan transfer informasi tentang pengatahuan terhadap penggunaan, penyimpanan serta pembuangan (DAGUSIBU) obat yang tepat. Dari serangkaian kegiatan tersebut diharapkan dapat memberikan kontribusi bagi masyarakat melalui pelayanan kesehatan dan pemberian informasi tentang pengetahuan DAGUSIBU obat. Sehingga dapat membantu dalam mencapai efek terapi yang diharapkan dan menurunkan biaya kesehatan (tidak masuk dalam pembiayaan $\mathrm{NHI}$ ) bagi para PMI yang akan melakukan medical check up reguler baik untuk pemeriksaan kesehatan rutin setiap 6 bulan maupun dengan tujuan perpanjangan kontrak kerja.

Berdasarkan latar belakang tersebut maka kegiatan ini bertujuan untuk memberikan pelayanan kesehatan secara gratis dan informasi tentang DAGUSIBU obat serta sebagai bentuk asesmen awal dan pencegahan penyakit bagi para pekerja migran Indonesia di Taipei.

\section{METODE}

Kegiatan pemeriksaan dan konsultasi kesehatan yang kami lakukan bertempatkan di tenda Bazar Pimpinan Cabang Istimewa Aisyiyah dan Muhammadiyah Taiwan pada klinik All in One dalam kegiatan Tabliq Akbar di Taipei Main Station. Kegiatan ini dilaksanakan pada tanggal 18 November 2018 dan 17 maret 2019 pada pukul 09.00 -15.00 Waktu Taiwan (WITA). Peserta berasal dari para pengunjung bazar yang merupakan Pekerja Migran Indonesia (PMI) di Taiwan yang berjumlah 51 orang.

Pelaksanaan pengabdian ini dilakukan dengan dua kegiatan, yaitu pemeriksaan kesehatan yang diikuti dengan konsultasi kesehatan dan edukasi DAGUSIBU (Dapatkan Gunakan Simpan Buang) obat yang tepat.

Pada pemeriksaan kesehatan dan konsultasi kesehatan, kami memulai dengan menyampaikan tujuan kegiatan pengabdian masyarakat ini. Para pengunjung yang bersedia berpartisipasi kemudian ajak untuk melakukan tes kesehatan di tenda bazar PCIM-PCIA. Sebelum pemeriksaan dilakukan maka dilakukan assessment pada peserta baik terkait keluhan, riwayat penyakit, dan riwayat pengobatan. Setelah itu dilakukan pemeriksaan tekanan darah dan penimbangan berat badan. Jika terdapat keluhan yang mengganggu maka dilakukan pemeriksaan lanjutan sesuai dengan kondisi peserta baik terkait tes kadar gula darah, asam urat, dan kolesterol. Setelah hasil pemeriksaan didapatkan maka peserta akan diberikan hasil pemeriksaan tersebut disertai dengan konsultasi kesehatan sesuai dengan kondisi peserta (KIE). Pada penyampaian materi edukasi DAGUSIBU kami lakukan bertepatan dengan pemeriksaan dan konsultasi kesehatan dimana peningkatan informasi ini dilakukan pada tahap akhir setelah peserta menyelesaikan konsultasi. Media informasi yang diberikan adalah berupa brosur dengan harapan dapat dibaca kembali dan mudah dibawa. Metode penyampaian yakni dengan metode sharing agar didapatkan diskusi yang lebih menyenangkan, melihat mayoritas adalah Pekerja Migran Indonesia (PMI).

Dengan adanya pemberian informasi ini diharapkan dapat menambah pengetahuan para Pekerja Migran Indonesia mengenai penggunaan, penyimpanan dan pembuangan obat dengan benar.

\section{HASIL DAN PEMBAHASAN}

Peserta berasal dari para pengunjung bazar yang merupakan Pekerja Migran Indonesia (PMI) di Taiwan yang berjumlah 51 orang. Dimana tim pengabdi dibantu oleh 2 tim anggota MPKU PCIM Taiwan sehingga kegiatan dapat berjalan dengan baik.

Peserta didapatkan dari dua pelaksanaan yaitupada tanggal 18 november 2018 sejumlah 36 peserta dan tanggal 17 maret 2019 sejumlah 15 peserta. Hal tersebut dikarena pelaksanaan 
mengikuti jadwal pelaksanaan tabliq akbar yang diadakan oleh perkumpulan organisasi muslim Taipei di Bazar Taipei Main Station (Gambar.1). Sehingga waktu pelaksanaan cukup singkat menyesuaikan waktu pelaksanaan bazar dimana bazar mengikuti jadwal tabliq akbar yang diadakan oleh organisasi keagamaan yang tidak dilakukan secara reguler.

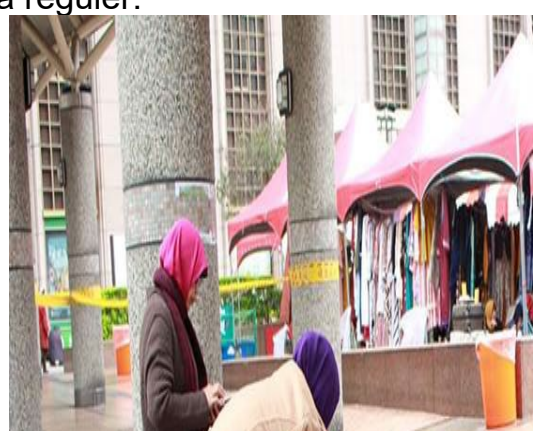

Gambar 1. Lokasi Bazar Tempat Pelaksanaan

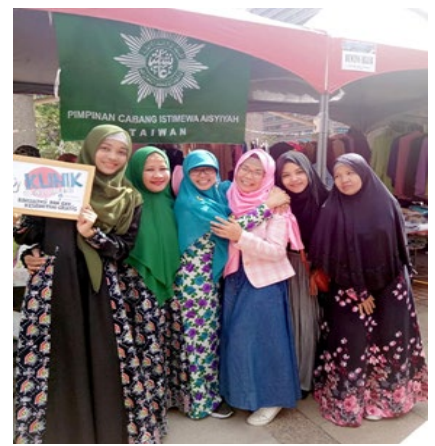

Gambar 2. Kegiatan Foto Bersama Pelaksanaan Edukasi

Sebagian besar peserta adalah perempuan $(94,1 \%)($ Gambar 2), ini sejalan dengan kegiatan pengabdian yang dilakukan pada salah satu ORTOM di Surakarta (Nugraheni et al., 2020). Hal tersebut dapat disebabkan karena dalam keluarga, perempuan (ibu) memiliki kesadaran dan daya proteksi yang lebih besar. Semua peserta melakukan pemeriksaan tekanan darah, namun pada beberapa pemeriksaan khusus hanya dilakukan pada peserta yang berkenan dan memiliki keluhan terkait saja (Gambar.3).

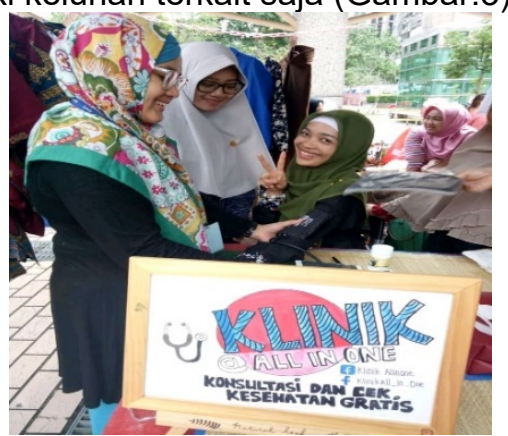

Gambar 3. Pelakssanaan Kegiatan Cek Kesehatan dan Konsultasi Kesehatan.
Dalam pelaksanaan pemeriksaan kesehatan didapatkan data dari pemeriksaan gula darah sebanyak 31 orang, asam urat sejumlah 17 orang, dan kolesterol sejumlah 4 orang.

Tidak semua peserta berkenan mengikuti pemeriksaan lebih lanjut karena para PMI hanya memiliki waktu terbatas dan peserta yang tidak memiliki keluhan yang mengganggu aktivitasnya. Para peserta menyampaikan beberapa keluhan pada saat sesi konsultasi, seperti mudah lelah, kurang istirahat, badan pegal terutama pada persendian. Dan didapatkan hasil pemeriksaan lanjutan di atas batas normal pada kadar gula darah (3 orang), kadar kolesterol (2 orang) dan asam urat (5 orang). Pemeriksaan gratis ini bertujuan untuk dapat menumbuhkan kesadaran individu dalam mencegah keparahan kondisi terutama terkait dengan penyakit degenerati sehingga dapat dilakukan deteksi awal sebagai bentuk pencegahan progresivitas(Hansur, Ugi, \& Febriza, 2020; Selano, Marwaningsih, \& Setyaningrum, 2020; Sukmana, Hardani, \& Irawansyah, 2020). Ritme kerja para PMI sangat mempengaruhi kualitas kesehatan baik secara fisik maupun mental. Sesuai penelitian pada para PMI di Korea, terdapat $5,5 \%$ yang memiliki tingkat keparahan depresi yang tinggi. Hal tersebut dipengaruhi oleh beberapa hal antara lain: tingkat pendidikan, tipe pekerjaan dan kesulitan melaksanakan ibadah di tempat kerja (Ade, 2020). Kesehatan mental sering tidak disadari karena tidak memberikan gejala yang nampak (Ade, 2020). Padalah kesehatan mental dapat mempengaruhi kesehatan fisik, salah satunya adala tingkat stess yang berpengaruh pada tekadan darah seseorang. Sehingga sangat penting untuk melakukan manajemen guna membantu menurunkannya (Pratiwi \& Edmaningsih, 2020).

Pemberian edukasi tentang DAGUSIBU dilakukan di akhir kegiatan pada setiap peserta dengan menggunakan media brosur (Gambar.4). Sehingga diharapkan peserta dapat menyimpan dan membaca dengan mudah kapanpun sesuai dengan kebutuhannya. Upaya peningkatan pemahaman masyarakat tentang DAGUSIBU dengan memberkan penyuluhan sangat efektif dilakukan guna menambah pengetahuan dan persepsi yang(Atmadani \& Hidayati, 2020; Djuria, 2018; Nugraheni et al., 2020). Berdasarkan hasil konsultasi kebutuhan PMI akan akses pada pelayanan kesehatan masih beragam. Hal tersebut dipengaruhi oleh beberapa faktor, antara lain: keterbatasan waktu (diberikan waktu libur beberapa jam saja), kesempatan untuk mendapatkan libur (satu kali dalam satu bulan sering kali digunakan untuk 
bersosialisas dan membeli kebutuhan seharihari sehingga pemenuhan untuk melakukan monitoring kesehatan tidak terpenuhi), kondisi pekerjaan, pengetahuan individu tentang kesehatan, dan kesadaran akan pentingnya menjaga kesehatan. Hal tersebut sejlan dengan penelitian pada PMI di korea (Ade, 2020). Oleh karena itu, adanya kegiatan pemeriksaan, konsultasi kesehatan gratis, dan pemberian informasi kesehatan disertai brosur tentang "Dapatkan, Gunakan, Simpan dan Buang Obat dengan Benar" sangat penting untuk dilakukan, terlebih untuk para Pekerja Migran Indonesia (PMI) di Taipei. Karena meskipun sarana prasarana kesehatan di Taipei dapat diakses dengan mudah dan cepat serta adanya keharusan setiap warga untuk memiliki asuransi kesehatan nasional/ National Health Insurance (NHI). Dari penelitian di Bali menujukan bahwa orang yang memiliki asuransi 2 kali lebih besar dapat melakukan swamedikasi yang tepat (Arimbawa, 2017), sehingga kemungkinan prevalensi swamedikasi pada PMI cukup banyak. Namun sayangnya akses pada sarana kesehatan masih belum dapat diakses oleh PMI yang bekerja di daerah (rural area) karena jauh dari pusat kota dan memiliki keterbatasan dalam mendapatkan waktu libur yang memungkinkan untuk memebuhi kebutuhan kesehatan secara mandiri.

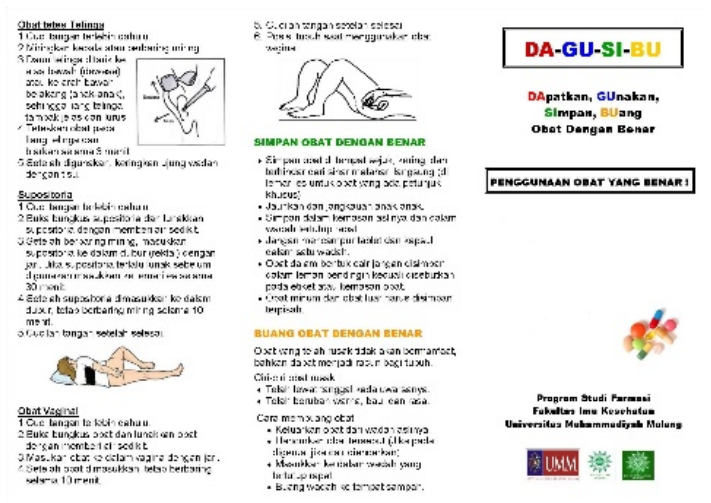

Gambar 4. Brosur DAGUSIBU

\section{SIMPULAN DAN SARAN}

Berdasarkan hasil pelasanaan dapat disimpulkan bahwa kemudahan akses dalam mendapatkan pelayanan kesehatan bagi para pekerja migran Indonesia di Taipei masih beragam. Adanya program pelayanan kesehatan dari lembaga non profit dalam memudahkan akses pelayanan kesehatan dasar sangat dibutuhkan. Kegiatan pengabdian masyarakat yang kami lakukan bekerja sama dengan tim MPKU dari Pimpinan Cabang Istimewa Muhammadiyah dan Aisyiyah Taiwan sangat efektif, karena mampu memenuhi kebutuhan pelayanan, konsultasi dan pemberian informasi kesehatan guna meningkatkan taraf kesehatan masyarakat terutama PMI di Taipei.

Dalam pemberian informasi kesehatan pada pekerja migran Indonesia (PMI), harus memperhatikan status pendidikan dan sosial. Hal tersebut dimaksudkan agar kita dapat menentukan penyampaian materi yang akan diberikan, sehingga didapatkan hasil yang efektif.

\section{UCAPAN TERIMAKASIH}

Kegiatan ini dapat dilaksananakan atas pembiayaan dari dana blockgrand Fakultas IImu Kesehatan Universitas Muhammadiyah Malang dan bekerjasama dengan Pimpinan Cabang Istimewa Aisyiyah-Muhammadiyah Taiwan.

\section{DAFTAR RUJUKAN}

Ade, S. (2020). Factors Related to Perceived Stress and Stress Responses among Indonesian Migrant Workers in South Korea. Seoul Natioal University. Retrieved from https://sspace.snu.ac.kr/handle/10371/166286

Arimbawa, P. E. (2017). Hubungan Kepemilikan Asuransi Kesehatan dengan Penggunaan Obat Rasional (POR) pada Pasien Swamedikasi. Jurnal IImiah Medicamento, 4(2), 118122.

https://doi.org/https://doi.org/10.36733/ medicamento.v4i2.866

Atmadani, R. N., \& Hidayati, I. R. (2020). Pelatihan Apoteker Cilik dan DaGuSiBu bagi Siswa SDN Losari di Singosari Kabupaten Malang. Jurnal Pengabdian UNDIKMA, $\quad 1(2)$, 77-81. https://doi.org/https://doi.org/10.33394/ jpu.v1i2.2966 Jurnal

Djuria, R. F. (2018). Peningkatan Pengetahuan Tentang Dagusibu Terhadap Kader Gerakan Keluarga Sadar Obat ( Gkso ) Desa Tanjung Gunung Bangka Tengah. Jurnal Kesehatan Poltekkes Pangkalpinang, 6(1). Retrieved from http://jurnal.poltekkespangkalpinang.ac .id/index.php/jkp/article/view/43/15

Hansur, L., Ugi, D., \& Febriza, A. (2020). IBM Pencegahan Penyakit Diabetes Melitus Di Kelurahan Tamarunang Kec Sombaopu Kabupaten Gowa Sulawesi Selatan. SELAPARANG Jurnal Pengabdian Masyarakat Berkemajuan, 4(1), $\quad$ 417-422. https://doi.org/10.31764/jpmb.v4i1.243 2

Jayanti, M., Arsyad, A., Farmasi, P. S., 
Ratulangi, U. S., Farmasi, J., Tinggi, S., \& Kesehatan, I. (2020). Profil Pengetahuan Masyarakat tentang Pengobatan Mandiri (Swamedikasi) Di Desa Bukaka Kecamatan Kotabunan Kabupaten Bolaang Mongondo Timur. Pharmacon Jurnal IImiah Farmasi, 9(1), 116-125.

https://doi.org/https://doi.org/10.35799/ pha.9.2020.27417

KDEI. (2021). Sebaran Data Pekerja Migran Indonesia di Taiwan. Retrieved March 17, 2021, from http://simpati.kdeitaipei.org/v2/index.php/infografik\#/tki

Ningsih, Y. E. (2018). Perubahan Posisi Indonesia Dalam Perburuhan: Studi Perbandingan Buruh Migran Masa Kolonial Dan Masa Reformasi. Sejarah Dan Budaya, 12(2), 194-199. https://doi.org/http://dx.doi.org/10.1797 7/um020v12i22017p194

Nugraheni, A. Y., Ganurmala, A., \& Pamungkas, K. P. (2020). Sosialisasi Gerakan Keluarga Sadar Obat: DAGUSIBU Pada Anggota Aisyiyah Kota Surakarta. Abdi Geomedisains, 1(1), 15-21. https://doi.org/10.23917/abdigeomedis ains.v1i1.92

Pratiwi, A., \& Edmaningsih, Y. (2020). Manajemen Stres Dan Ansietas Untuk Penurunan Tekanan Darah. SELAPARANG Jurnal Pengabdian Masyarakat Berkemajuan, 4(1), 679683.

https://doi.org/10.31764/jpmb.v4i1.297 7

Putra, G. D. E., Lestari, A., Firlyani, R. D., Fauzan, M. F., Annafisa, T., Bawazier, N. A., ... Sari, F. P. (2017). Pengetahuan Mahasiswa Di Surabaya Terhadap Penggunaan Antasida. Jurnal Farmasi Komunitas, 4(2), 50-55. Retrieved from http://journal.unair.ac.id/downloadfullpapers-jfk6d13321420full.pdf

Selano, M. K., Marwaningsih, V. R., \& Setyaningrum, N. (2020). Pemeriksaan Gula Darah Sewaktu (GDS) dan Tekanan Darah kepada Masyarakat. Indonesian Journal of Community Services, 2(1), 38-45. https://doi.org/10.30659/ijocs.2.1.38-45

Sukmana, D. J., Hardani, H., \& Irawansyah, I. (2020). Pemeriksaan Kesehatan Gratis sebagai Upaya Peningkatan Kesadaran Masyarakat terhadap Deteksi Dini Penyakit Tidak Menular. Indonesian Journal of Community Services, 2(1), 19-26. https://doi.org/10.30659/ijocs.2.1.19-26
Ulfa, A. M., JK, E. E., \& Sobirin. (2018). Penyuluhan Penerapan Dagusibu Bentuk Sediaan Suppositoria di Puskesmas Gadingrejo Pringsewu. Jurnal Pengabdian Farmasi Malahayati, 3(2), 14-19. Retrieved from http://www.ejurnalmalahayati.ac.id/ind ex.php/pengabdianfarmasi/article/view/ 3803 